Call for Correspondence JNCCN is committed to providing a forum to enhance collaboration between academic medicine and the community physician. We welcome comments about the NCCN Clinical Practice Guidelines in Oncology (NCCN Guidelines), articles published in the journal, or any other topic relating to cancer prevention, detection, treatment, supportive care, or survivorship.

Please send correspondence to JNCCN.edmgr.com or to JNCCN@nccn.org.

Letters should be no more than 400 words, with no more than 5 references if included. Please include the full names, degrees, and affiliations of all letter authors and a phone number or e-mail address for contact.

Letters are considered for publication as space allows. NCCN reserves the right not to publish correspondence for any reason it deems appropriate. All letters are subject to editing and/or abridgment.

\title{
Letter to the Editor: Chicken Noodle Soup (Capsule) for the Soul?
}

Re: Sriram Yennurajalingam, Nizar M. Tannir, Janet L. Williams, et al. A Double-Blind, Randomized, PlaceboControlled Trial of Panax Ginseng for Cancer-Related Fatigue in Patients with Advanced Cancer. J Natl Compr Canc Netw 2017;15(9):1111-1120.

We enjoyed reading the article, "A Double-Blind, Randomized, PlaceboControlled Trial of Panax Ginseng for Cancer-Related Fatigue in Patients with Advanced Cancer" by Yennurajalingam et al. ${ }^{1}$ This study did not prove ginseng to be effective for cancer-related fatigue. We suggest an additional study limitation based on a traditional use of ginseng not cited in the research.

In traditional Chinese medicine, ginseng is used in the form of tea. This makes us question whether there is some component to the use of ginseng in this form, compared with extract, that is lost in the manufacturing process. Traditionally, ginseng root is chopped and placed into an empty cup. Water is boiled and allowed to cool. The water is then poured into the cup and steeped for 5 to 10 minutes or longer, depending on desired strength. Finally, the ginseng is strained out and the tea is ready for consumption. $^{2}$

This study and other similar studies involve the process of manufacturing ginseng extract into capsule form. Although this process of creating a pill ensures a standardized dose of ginseng, it does not use the traditional mode of administration through tea. A phase III study similar to this one by Barton et $\mathrm{al}^{3}$ used capsules containing a standardized amount of American ginseng to treat cancer-related fatigue. The results showed no measurable difference in fatigue between the placebo and ginseng groups at 4 weeks, but there was a statistically significant difference at 8 weeks. Another randomized, double-blind, controlled clinical trial by Kim et $\mathrm{al}^{4}$ compared the use of Panax ginseng versus placebo in patients with idiopathic chronic fatigue, with negative results. Similarly, Barton et $\mathrm{al}^{5}$ performed a phase III trial using Ginkgo biloba extract capsules in patients with cancer and cognitive dysfunction which did not show efficacy.

We hypothesize that if the herbals used in these studies had been prepared in the traditional manner, they may have been more efficacious. A traditional homeopathic remedy used in the United States for illness is chicken noodle soup. Would a capsule of lyophilized chicken noodle soup offer the same comforting effect as a warm, hearty bowl of it? Perhaps using ginseng in the traditional manner would deliver benefits beyond its capacity in extract form.

\section{References}

1. Yennurajalingam S, Tannir NM, Williams JL, et al. A Double-blind, randomized, placebocontrolled trial of Panax ginseng for cancer related fatigue in patients with advanced cancer J Natl Compr Canc Netw 2017;15:1111-1120.

2. How to Make American Ginseng. www.wikihow. com. Available at: https://www.wikihow.com/ Make-American-Ginseng-Tea. Accessed October 17, 2017.

3. Barton D, Liu H, Dakhil S, et al. Wisconsin ginseng (Panax quinquefolius) to improve cancerrelated fatigue: a randomized, double-blind trial, N07C2. J Natl Cancer Inst 2013;105:1230-1238.

4. Kim HG, Cho JH, Yoo SR, et al. Antifatigue effects of Panax ginseng C.A. Meyer: a randomised, double-blind, placebo-controlled trial. PLoS ONE 2013;8:e61271.

5. Barton DL, Burger K, Novotny PJ, et al. The use of Ginkgo biloba for the prevention of chemotherapy-related cognitive dysfunction in women receiving adjuvant treatment for breast cancer, N00C9. Support Care Cancer 2013;21:1185-1192.

Lindsey A. Kluck, APRN, CNP Mayo Clinic, Rochester

E-mail: kluck.lindsey@mayo.edu Ronald S. Go, MD

Mayo Clinic, Rochester

E-mail: go.ronald@mayo.edu doi: 10.6004/jnccn.2017.7060 


\section{Author's Reply to Letter to the Editor: "Chicken Noodle Soup (Capsule) for the Soul?"}

\begin{abstract}
Author's Reply to Lindsey A. Kluck and Ronald S. Go's Letter to the Editor re: Sriram Yennurajalingam, Nizar M. Tannir, Janet L. Williams, et al. A Double-Blind, Randomized, PlaceboControlled Trial of Panax Ginseng for Cancer-Related Fatigue in Patients with Advanced Cancer. J Natl Compr Canc Netw 2017;15(9):1111-1120.
\end{abstract}

We would like to thank Lindsey A. Kluck, APRN, CNP, and Ronald S. Go, $\mathrm{MD}$, for their interest in the recently published article, "A Double-Blind, Randomized, Placebo-Controlled Trial of Panax Ginseng for Cancer-Related Fatigue in Patients With Advanced Cancer." In this article we reported that standardized Panax ginseng in 400-mg capsules taken orally twice daily was not significantly superior to placebo after 4 weeks of treatment.

Kluck and Go state that, "In traditional Chinese medicine, ginseng is used in the form of tea" to treat various health conditions, and that our study, and others that are similar, use ginseng in capsule form. After examining other studies using herbals prepared in capsule form, Kluck and Go hypothesize that the results may be more supportive if the herbals were prepared in the traditional manner. They also liken the use of ginseng in the traditional formula as a tea to the use of chicken soup for treating illness.

We acknowledge the correspondents' observation as an additional limitation that was not discussed within the article. However, our study, as well as those by Barton et $\mathrm{al}^{2}$ and Kim et $\mathrm{al},{ }^{3,4}$ used standardized ginseng in cap- sule form for various reasons: (1) to account for various active components of ginseng, (2) because the standardized processing can be scientifically replicated in future studies, and (3) to obtain adequate blinding for odor as well as taste. Unfortunately, our study showed that standardized Panax ginseng in 400mg capsules taken orally twice daily was not significantly superior to placebo after 4 weeks of treatment. Future studies may consider the use of tea instead of a capsule. However, one of the concerns regarding the use of ginseng in a traditional tea preparation is that it may be difficult to mask the odor and taste of ginseng tea.

\section{References}

1. Yennurajalingam $S$, Tannir NM, Williams JL, et al. A Double-blind, randomized, placebocontrolled trial of Panax ginseng for cancerrelated fatigue in patients with advanced cancer. J Natl Compr Canc Netw 2017;15:1111-1120.

2. Barton D, Liu H, Dakhil S, et al. Wisconsin ginseng (Panax quinquefolius) to improve cancerrelated fatigue: a randomized, double-blind trial, N07C2. J Natl Cancer Inst 2013;105:1230-1238.

3. Kim YH, Lim Y, Cho JY, et al. Korean red ginseng to improve cancer-related fatigue in colorectal cancer patients with FOLFOX chemotherapy: a randomized, double-blind, placebo-controlled, parallel, multicenter trial, NCT02039635 [abstract]. J Clin Oncol 2017;35(Suppl):Abstract 10008.

4. Kim HG, Cho JH, Yoo SR, et al. Antifatigue effects of Panax ginseng C.A. Meyer: a randomised, double-blind, placebo-controlled trial. PLoS ONE 2013;8:e61271.

Sriram Yennurajalingam, MD

The University of Texas

$\mathrm{MD}$ Anderson Cancer Center

E-mail: syennu@mdanderson.org

doi: 10.6004/jnccn.2017.7061 